\title{
NEEDLE STICK INJURIES; CONCEPT \& HANDLING AMONG JUNIOR DENTIST
}

1. BDS, FCPS

Assistant Professor

Oral \& Maxillofacial Surgery

Department

Faculty of Dentistry,

LUMHS, Jamshoro

2. BDS, MSc

Assistant Professor

Department of Community Dentistry

Faculty of Dentistry,

LUMHS, Jamshoro

3. BDS, (MSc- Trainee)

Department of Community Dentistry

Faculty of Dentistry,

LUMHS, Jamshoro

4. BDS, (MSc- Trainee)

Department of Community Dentistry

Faculty of Dentistry,

LUMHS, Jamshoro

Correspondence Address:

Dr. Suneel Kumar Punjabi

Flat No: $3073^{\text {rdfloor Citizen Plaza }}$

Opp Aga Khan Hospital

Main Jamshoro Road,

Qasimabad, Hyderabad

drsunilpanjabi@yahoo.com

Article received on:

08/08/2016

Accepted for publication:

20/10/2016

Received after proof reading:

18/01/2017

\section{INTRODUCTION}

Needle-stick and Sharp Injuries (NSIs) are fortuitous skin piercing injury caused by sharp instruments in a medical $\&$ in dental setups. ${ }^{1}$

Healthcare Workers i.e. surgeons, dentist, assistant, physicians and nurses face greater risk of work-related exposure to blood, which can cause transmission of pathogens resulting an infection and harmful consequences for their health. Hepatitis B, Hepatitis C, and Human Immunodeficiency Virus (HIV) are of great concern because they are capable of causing considerable morbidity or death. ${ }^{1}$

The usually risky site of such a professional exposure is skin injury by which infections can get entry into body. ${ }^{1}$

\section{Dr. Suneel Kumar Punjabi', Dr. Munir Ahmed Banglani², Dr. Priya ${ }^{3}$, Dr. Nayab Mangi ${ }^{4}$}

STRCT... Objectives: To evaluate the concepts \& handling of needle stick injuries among (a) The study population of 200 dentists of Hyderabad, Sindh. Questionnaire designed to obtain information about their concepts and universal precautions guidelines, $16(8 \%)$ use safety devices to dispose used sharp objects. injury. $37(18.5 \%)$ had said that they will contact to medical $53(26.5 \%)$ will consult with their physician \& 78(39\%) said that they will manage themselves. Conclusion: this study confirm that junior dentists of Hyderabad experience the NSIs but are preventing \& reporting all NSIs. Through Support, counseling and tutoring by their Occupational Key words: $\quad$ Needle stick injury, Post exposure prophylaxis, Blood born diseases
The occurrence of such accidents is probably about 800,000 cases in the United State of America only. ${ }^{2}$

Further surveys approximate the rates of injuries on international level to distress about 3.5 million entities. ${ }^{1}$ Healthcare workers, physicians \& nurses are particularly at threat ${ }^{3}$, a research in American dentists \& surgeons shows that nearly about every surgeon has experienced injury at least once during their training. ${ }^{4}$

The routine use of sharp instruments i.e. hand, rotary, surgical, hypodermic needles, suture needles, and lancets in dental treatment, the presence of saliva \& blood, various bacterial flora in the mouth \& needle design, recapping practice, maneuver needles in patient linked work, conflict between HCWs or sharps, while 
cleaning, handling/transfer of specimens, passing/handling devices or failure to dispose of the needle in puncture proof boxes, all contribute to the hazardous nature of the dental workplace for blood-borne infections. ${ }^{5,6}$ According to some studies, there is $27.5 \%$ prevalence of $\mathrm{NSI}, 52.5 \%$ of the dental professionals were unaware of the safety devices available in the market to prevent NSls, and Preventing NSls is a challenge faced in virtually every medical work place. ${ }^{6}$

In a dental environment, the burden of NSIs and SIs can be reduced when a dental professional abides by the current and universally accepted standards, precautionary measures against NSIs and use of safety containers for disposing sharp objects. ${ }^{6}$

All healthcare facilities must have an infection control program in their settings through a functioning hospital infection control board. The aim of this study was to assess the knowledge and handling of NSIs among junior dental professionals of city Hyderabad.

\section{METHODOLOGY}

The descriptive Cross Sectional study was carried out on Dental House surgeons and Postgraduates of city Hyderabad. A self-administered 10 close ended questions were conducted to assess concepts, attitude and handling of Needle stick injuries in their practice. Questionnaire ${ }^{1}$ taken to evaluate Concept, prevalence \& handling of needle stick injuries, i.e. diseases that could be transferred by NSIs, which instruments can cause NSIS, when NSIs mostly occurs etc.

In this survey 200 respondents were enrolled, working in private or public settings of Hyderabad, Sindh, from June 2015 to January 2016.

After obtaining informed consent, solo investigator collected questionnaire data by meeting with respondents. No tracking method was applied to wind up who answered and who did not, in order to guarantee imprecision.

Data compilation was done by using the SPSS version 22.0 to evaluate the data using descriptive statistics. Descriptive statistics were computed and differences between groups were assessed and showed in the form of graphs \& tables.

\section{RESULTS}

Overall 200 respondents were entitled in this study, 100 (50\%) were dental house surgeons and $100(50 \%)$ were post graduates, in which male dentist were 85 (42.5\%) and female dentist were 115 (57.5\%).

$75(37.5 \%)$ of them were working in Oral Surgery department, $53(26.5 \%)$ in Operative Dentistry, 35 (17.5\%) in Orthodontics, 22(11\%) in Periodontology, and 15(7.5\%) in Prosthodontics. (As shown in Table-I)

\begin{tabular}{|l|c|}
\hline \multicolumn{1}{|l|}{ Gender } & Variables \\
\hline Male & $85(42.5 \%)$ \\
\hline Female & $115(57.5 \%)$ \\
\hline Designation & \\
\hline Dental House Surgeons & $100(50 \%)$ \\
\hline Dental Postgraduates & $100(50 \%)$ \\
\hline Department & \\
\hline Oral Surgery & $75(37.5 \%)$ \\
\hline Operative Dentistry & $53(26.5 \%)$ \\
\hline Orthodontics & $35(17.5 \%)$ \\
\hline Periodontology & $22(11 \%)$ \\
\hline Prosthodontics & $15(7.5 \%)$ \\
\hline \multicolumn{2}{|c|}{ Table-I. Demographic Variable } \\
\hline
\end{tabular}

172 (86\%) were immunized against HBV, 30 (15\%) had screened HBV titer, $77(38.5 \%)$ had idea about transmission of Hepatitis B, 89 (44.5\%) about Hepatitis C, \& 34 (17\%) about HIV/AIDS by NSI. $63(31.5 \%)$ said that NSI occurs with hand instruments, 17 (8.5\%) with rotary instruments, 120 (60\%) surgical instruments. 168 (84\%) had knowledge about universal precautions guidelines, 16 (8\%) use safety devices to dispose used sharp objects. 189 (94.5\%) had faced NSIs ever. 97 (48.5\%) had knowledge about post exposure prophylaxis in the management of needle stick injury. $37(18.5 \%)$ had said that they will contact to medical emergency room 
if they expose to NSI, $32(16 \%)$ will contact to oral surgery department, $53(26.5 \%)$ will consult with their physician \& 78 (39\%) said that they will manage themselves. Table-Il presenting the questionnaires distribution with answers, asked by researcher, $37.50 \%$ experienced that NSIs mostly occurs during dental procedures, $44.50 \%$ experienced that NSIs occurs during recapping the needle, and $18 \%$ experienced NSI during disposal of needle. As shown in Figure-1.

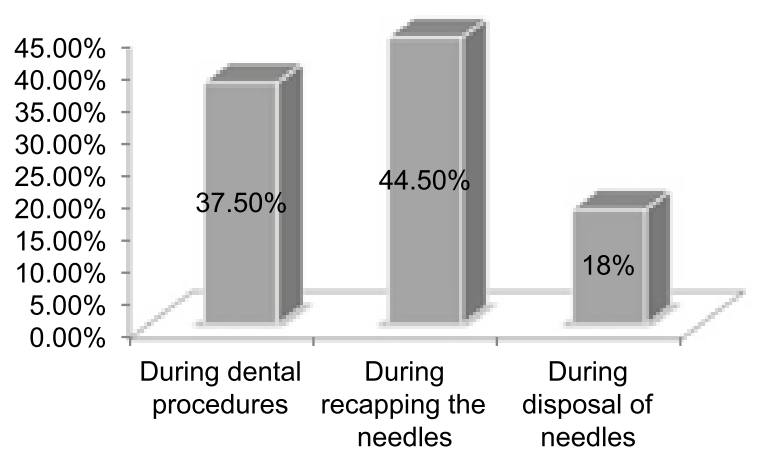

Figure-1. Occurrence of NSIs

\section{DISCUSSION}

The awareness regarding problems of professional exposure has begun many decades ago, as it was approximated that more than 14,000 inadvertent deaths occurred in the work place in the United States in $1970 .{ }^{7}$ This enterprises many organizations that devise and inflict the guiding principle of work-related safety such as the interior for disease control \& prevention. (IDCP) has estimated up to 500,000 per-cutaneous professional injuries every year in the US, about $1 \%$ of patients who tested positive for HIV. ${ }^{8}$ As a result there is high prevalence of injuries. It was stated that in the USA, more than 50 cases of occupational transmission of HIV \& three folds of this number are the cases of possible seroconversion in $\mathrm{HCWs}{ }^{9}$

Reported frequency of Hepatitis B \& Hepatitis C is $4 \% \& 6 \%$ respectively in Pakistani population. ${ }^{10}$ Needle stick injuries are one of the common and high risk cause leading to transmission of Hepatitis B \& C infections in dental health care

\begin{tabular}{|c|c|c|}
\hline Questions & Yes & No \\
\hline 1- Are you immunized against HBV? & $172(86 \%)$ & $28(14 \%)$ \\
\hline 2- Have you ever screened for HBV Titer? & $30(15 \%)$ & $170(85 \%)$ \\
\hline A- Hepatitis B & $77(38.5 \%)$ & $123(61.5 \%)$ \\
\hline B- Hepatitis C & $89(44.5 \%)$ & $111(55.5 \%)$ \\
\hline $\mathrm{X}-\mathrm{HIV} / \mathrm{AIDS}$ & $34(17 \%)$ & $166(83 \%)$ \\
\hline $\begin{array}{l}\text { A- Hand instruments } \\
\text { ( Explorer, Probe, Endodontic instruments) }\end{array}$ & $63(31.5 \%)$ & $137(68.5 \%)$ \\
\hline $\begin{array}{l}\text { B- Rotary instruments } \\
\text { (Air motor, Endodontic instruments) }\end{array}$ & $17(8.5 \%)$ & $183(91.5 \%)$ \\
\hline $\begin{array}{l}\text { C-Surgical instruments } \\
\text { (scalpel, Scissors, Elevators, Hypodermic } \\
\text { needles, Suture needles, Lancets) }\end{array}$ & $120(60 \%)$ & $80(40 \%)$ \\
\hline 6- Do you use safety devices to dispose used sharp objects? & $16(8 \%)$ & $184(92 \%)$ \\
\hline 7- Have you ever faced NSI? & $189(94.5 \%)$ & $11(5.5 \%)$ \\
\hline $\begin{array}{l}\text { 8- Do you have knowledge about post exposure prophylaxis in the } \\
\text { management of needle stick injury? }\end{array}$ & $97(48.5 \%)$ & $103(51.5 \%)$ \\
\hline \multicolumn{3}{|l|}{ 9- Whom do you contact after needle stick injury? } \\
\hline A- Medical emergency room & $37(18.5 \%)$ & $163(81.5 \%)$ \\
\hline B- Oral surgery department & $32(16 \%)$ & $168(84 \%)$ \\
\hline C- Consult with your physician & $53(26.5 \%)$ & $147(73.5 \%)$ \\
\hline D- Manage your self & $78(39 \%)$ & $122(61 \%)$ \\
\hline
\end{tabular}


providers ${ }^{11}$, which can occur during preparation of syringes for local anesthetic infiltration before dental procedure, during actual intervention and at the time of disposal of needles and sharps. ${ }^{12}$

Surveys conducted among North American DHCPs showed about $01 \mathrm{NSI}$ per year ${ }^{13}$. In Scotland frequency of NSI was shown as 1.7 per year. $^{14}$

However, frequency of needle stick injuries is greater in Pakistan. ${ }^{15}$

In this study of $\mathrm{NSI}$ among qualified dentists with 100 house surgeons and 100 post graduate residents, $37.50 \%$ had needle stick injury during the dental procedure, $44.50 \%$ had during the recapping of needles and $18 \%$ had during the disposable of needles. This seemingly higher incidence appears to be due to lack of awareness of risks and knowledge regarding safety guidelines.

Whilst comparing our data with other studies ${ }^{1,16}$ there were no obvious variations in the distinctiveness of the NSIs. The circumstances of the injuries differ with the type of instruments. Due to the variation between studies, it impossible to quantitatively combine their outcomes; nonetheless, some general themes emerge, i.e. needle-stick injuries are widespread and are often under-reported, when levels of exposure have been examined.

\section{CONCULSION}

The results of current study shows that junior dental students in Hyderabad Are familiar with NSIs, however they failed to identify appropriate management and reporting of such injuries, hence, it necessitate upgrading of knowledge in the clinical training, in particular more instructional time dedicated to prevention and management of NSIs. In addition, tutoring, competence based training should be considered. They should also be made aware of the current procedure and protocol. Support and counseling should be provided by their Occupational Health Department. It is the liability of academic organizations to facilitate Regular health checkups, tests for serum antibodies and antigens of $\mathrm{HBV}, \mathrm{HCV}$, HIV and appropriate hepatitis $B$ vaccination are mandatory for occupational safety of healthcare workers to improve the system and establish safety protocols for clinical performance.

Copyright (C) 20 Oct, 2016.

\section{REFERENCES}

1. Hashmi A, Al Reesh SA, Indah. Prevalence of Needlestick and Sharps Injuries among Healthcare Workers, Najran, Saudi Arabia. Epidemiol. 2012; 2:117. doi:10.4172/2161-1165.1000117.

2. Prüss-Ustün A, Rapiti E, Hutin Y. Estimation of the global burden of disease attributable to contaminated sharps injuries among health-care workers. Am J Ind Med. 2005; 48: 482-490?

3. Exposure prevention information network data reports. University of Virginia: International Health Care Worker Safety Center. EPINet (1999).

4. Makary MA, Al-Attar A, Holzmueller CG, Sexton JB, Syin $D$, et al. Needle-stick injuries among surgeons in training. N Engl J Med. 2007; 356: 26932639.

5. Wilburn SQ. Needle sticks and sharps injury prevention. Online J Issues Nurs. 2004; 30: 5.

6. Jaer Lee J, Heng Kok S, Jung Cheng S, Deh Lin L, et al. Needle stick and sharps injuries among dental healthcare workers at a university hospital. J Formosan Med Asso. 2014; 113: 227e233.

7. Gaballah K, Warbuton D, Sihmbly K, Renton T. Needle stick injuries among dental students: risk factors and recommendations for prevention. Libyan J Med. 2012, 7: 17507 - http://dx.doi.org/10.3402/ljm.v7i0.17507.

8. Trape-Cardoso M, Schenck P. Reducing percutaneous injuries at an academic health center: a 5-year review. Am J Infect Control. 2004; 32: 301-5.

9. Centers for Disease Control and Prevention. Sample screening and device evaluation forms; 2002. Available from: http:// www.cdc.gov/oralhealth/ infectioncontrol/forms.htm [cited 14 December 2006].

10. Thurn J, Willenbring K, Crossley K: Needlestick injuries and needle disposal in Minnesota physicians' offices. Am J Med 1989, 86(5): 575-79.

11. Abbas Z, Jafri W, Shah SHA, Khokhar N, Zuberi SJ. PGS Consensus Statement on management of Hepatitis B Virus Infection 2003. J Pak Med Assoc 2004; 54 : 150-58. 
12. David HT, David YM. Living with needle stick injuries. J Can Dent Assoc 1997; 63: 283-86.

13. Porter KM, Scully C, Porter S, Theyer Y. Needle stick injuries in dental personnel. J Am Dent Assoc 1990; 18: $258-62$.

14. Siew C, Gruninger SE, Miaw CL, Neidle E A. Percutaneous injuries in practicing dentists. A prospective study using a 20-day diary. J Am Dent Assoc 1995; 126: 1227-34.
15. Jan S, Akund T, Akhtar MJ, Shaikh JM. Needle stic i9njuries among dental health care providers: A survey done at Hyderabad and Karachi. Pakistan Oral \& Dent J. 2014; 34: 339-343.

16. Kermode M, Jolley D, Langkham B, Thomas M, Crofts N. Occupational exposure to blood and risk of blood borne virus infection among health care workers in rural North Indian settings. Am J Infect Control. 2005; 33: 34-41.

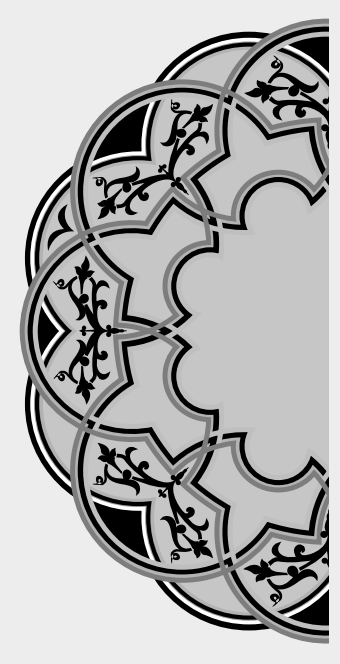

\title{
"One lie is enough to question all truths."
}

\author{
Anonymous
}

AUTHORSHIP AND CONTRIBUTION DECLARATION

\begin{tabular}{|c|l|}
\hline Sr. \# & \multicolumn{1}{|c|}{ Author-s Full Name } \\
\hline 1 & Dr. Suneel Kumar Punjabi \\
2 & Dr. Munir Ahmed Banglani \\
3 & Dr. Priya \\
4 & Dr. Nayab Mangi \\
\hline
\end{tabular}

